\title{
RoSunLand: a Sustainable Self-Construction Village for Emigrant African Workers in Italy
}

\author{
Alessia Bianco $^{1, a}$, Vittorio Ceradini ${ }^{1, b}$ \\ Alessandra Suraci ${ }^{1, \mathrm{c}}$, Antonio Di Paola ${ }^{1, \mathrm{~d}}$ \\ ${ }^{1}$ Mediterranea University of Reggio Calabria, via Melissari n. 189100 Reggio Calabria-Italy \\ aalessia.bianco@unirc.it, bvittorio.ceradini@unirc.it \\ calessandrasuraci@virgilio.it, ${ }^{d}$ antonio.dipaola@virgilio.it
}

Keywords: Italy, Rosarno, Self-Construction, Sustainable Architecture.

\begin{abstract}
The paper regards a research, aimed to purpose an architectonic project to realize a self-construction village in a farming town, Rosarno, located in Calabria, the Southernmost Italian Region. The project is purposed in alternative to a temporary camp, realized by the army, after a large riot of African emigrants, who live in this area and work in the oranges plantations, with scarce protection of their rights and forced to live inside old abandoned industrial buildings. The protest, determined by inhuman life and working conditions of these young Africans, however, did not find an appropriate solution by governmental institutions, which have built a refugee camp, in order to receive, but also to control them, relegating them away from the city. Our project proposal, RoSunLand, wants to be an alternative solution, capable to be expression of a culture, which accepts diversity as a humanizing wealth and to remind that work is one of most relevant social means to achieve dignity.
\end{abstract}

\section{Introduction}

Rosario is a small town in Southern Italy, known for its extensive citrus fruits cultivation, thanks its peculiar climate; its geographical location and the opportunity, although only seasonal, to work attracts young African emigrants, who, especially during the citrus harvest time, not rarely become more numerous then resident population.

This circumstance, for several decades, has produced a miserable and shameful working and living condition, and were in 2010 the reason of an uprising of black African emigrants. Following the uprising, put down through an intervention of the army, contested for supposed violence and abuse, a temporary refugee camp was built, doing an irrational assembling of prefabricated containers. To realize it, a hill was leveled and an ancient and beautiful citrus grove was destroyed. The camp, entirely fenced with a wire mesh, has not socialization spaces, there is not a bench and even a cable to hang the washing. This approach, in our opinion, is not only expression of a social system, which is unable to listen and include diversity, but also contrasts with the respect of human dignity and ethic equity. So, with this research we want propose an alternative project for a village inspired by the book, The City of Sun, written by a leading European philosopher of the seventeenth Century, born in Calabria, Tommaso Campanella, who describes a city founded on fairness, liberty and dignity. For these ideas, Campanella was persecuted and imprisoned for 27 years.

Our village is planned for host African emigrant seasonal workers and it is technologically projected with a timber framed houses, because this system is very common in constructive African traditions, cheap, easy to assemble and, above all, capable of be made in self-construction. The project tries to inspire itself to five principles of sustainable architecture: - innovation and transferability; ethical standards and social equity; - environmental quality and resource efficiency; - economic compatibility; - contextual and aesthetic impact.

We called this our village RoSunLand (Rosarno+Sun+Land), because it is inspired to the Campanella's book, The City of Sun, because wealth of oranges plantations of Rosarno is a gift of sun 
and because, not only the plan is in the shape of sun, but the project also includes the sun (solar panels) as a way to guarantee the energy self-sufficiency of the village [1].

\section{The proposal}

RoSunLand is an acronym, consisting of the words Rosarno, Sun and Land; in fact the main theme of this project proposal is the sun as energy source, inspiration of forms and ideas. It is not a coincidence that one of most relevant Tommaso Campanella's books on human rights is titled The City of Sun. Our village, designed to be placed in the same area where the current camp is locatd; it is composed by small one stories buildings, has the shape of a sun, because it wants to promote socialization and sharing, with a strong emphasis on joint activities; for this reason, for example, we purpose to encourage common meals in the main building, which has a central kitchen where everyone can cook, for himself and others, dishes from his African Country [2]. Another important buildings for the social life is an indoor multi-purpose building (to meet, celebrate, pray, discuss their problems, receive visitors), a small bar and a multi-sport field, considering that over than $70 \%$ of these emigrants are under 25 years old. Each dormitory has internal bathroom, including a little laundry, in respect of personal individuality, but considering at same time the need to share spaces and sources, also because they are usually not married or prefer to leave their families in their fatherlands, because they are only temporary seasonal workers. The camp has a reception office with an infirmary, benches and a bike parking, because the emigrants mainly go to work by bike. There is no a fence, only a small border of boxwood, interspersed with wind-powered street lights, identifies the perimeter of the RoSunLand village. We purpose to replant orange orchards, destroyed to do the current camp, and the emigrants will have a specific area, where they can grow themselves a vegetable garden, considering that a lot of them were farmers in Africa and the African diet is based on plant products, also Rosarno is a particularly fertile and the climate is ideal for vegetable cultivations. The village, being built with small timber buildings, will be aesthetically compatible with this beautiful area, filled with orange orchards and secular olive groves. The village will have energy independence, thanks to solar panels and wind turbines; is also provided a water recycling system of rainwater for non-drinking use.

The village is designed technologically with timber framed houses (Fig. 1), very common in the constructive African tradition, because they are fast and easy to assemble, for this reason the instructions of our houses will have only image and will have not text, because half of emigrants is illiterate and $10 \%$ speaks only his tribal languages. These houses have to be simple in their shape and module, to be realized in self-construction; in this way the emigrants, which will participate to build the village, should be recognized by the Italian Institutions as workers and so they can emancipate themselves from the condition of illegal emigrants [3] (Fig. 2). They will are designed to apply technological solutions aimed to improve energy performance [4], for example for the indoor surface of outside walls will be used panels made by recycled sheep's wool fibers and surface of internal walls will be built with the "incannucciato", a traditional technique, used in Calabria, able to insulate walls, using a texture made crossing river canes (Figg. 3-4). The idea of this framed house is inspired by a simple framed house, built after the earthquake of 1908, placed just outside the current camp, which is fully integrated to these beautiful countryside, that, in antiquity, was called water spring thanks its luxuriance. This timber framed house, still used today, demonstrates the compatibility of solution that we would use in this context [5], both in terms of durability and aesthetic impact of technological context (Fig. 5). Moreover we have to remind timber framed technology is also suitable for the emergency conditions, considering that it is traditionally used in occasion of many exceptional events and disasters (earthquakes, floods, and so on), because it is safe against earthquakes, quick to assemble, very durable if subject of maintenance, but also because it can be inself-construction built, even by unskilled operators; it is therefore a highly useful technology in case of emergencies. 


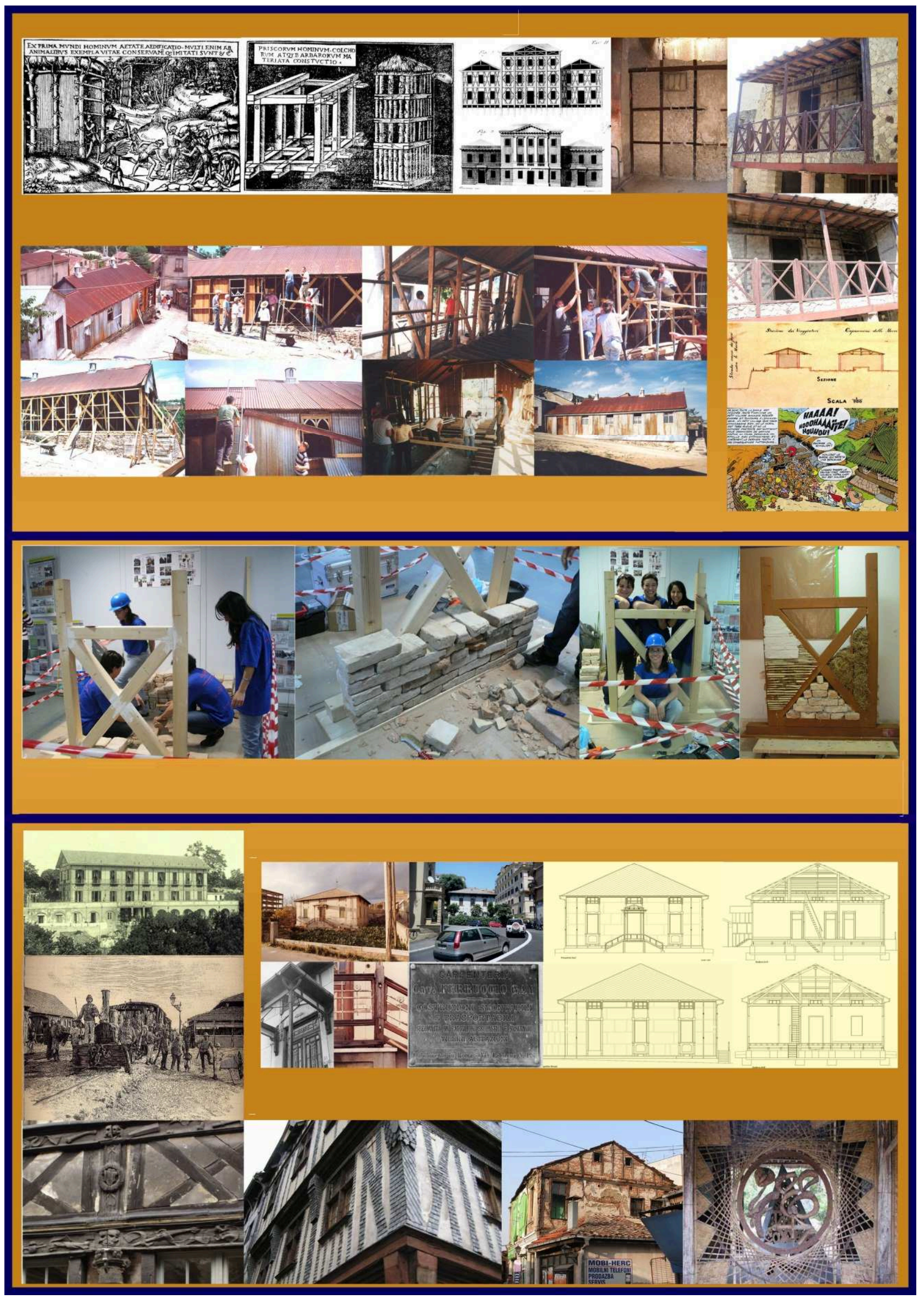

Fig. 1 - Innovation and transferability 

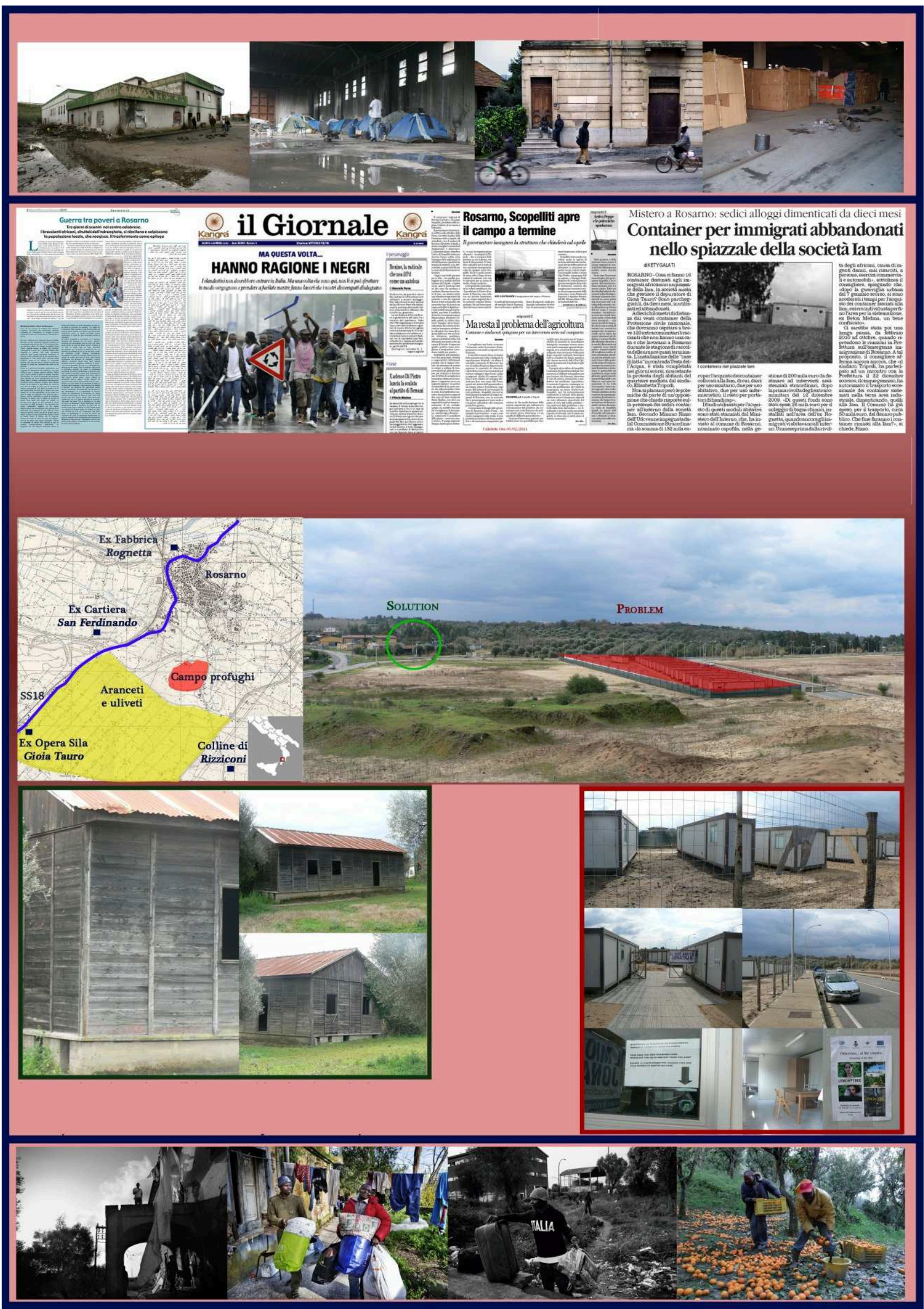

Fig. 2 - Ethical standards and social equity 


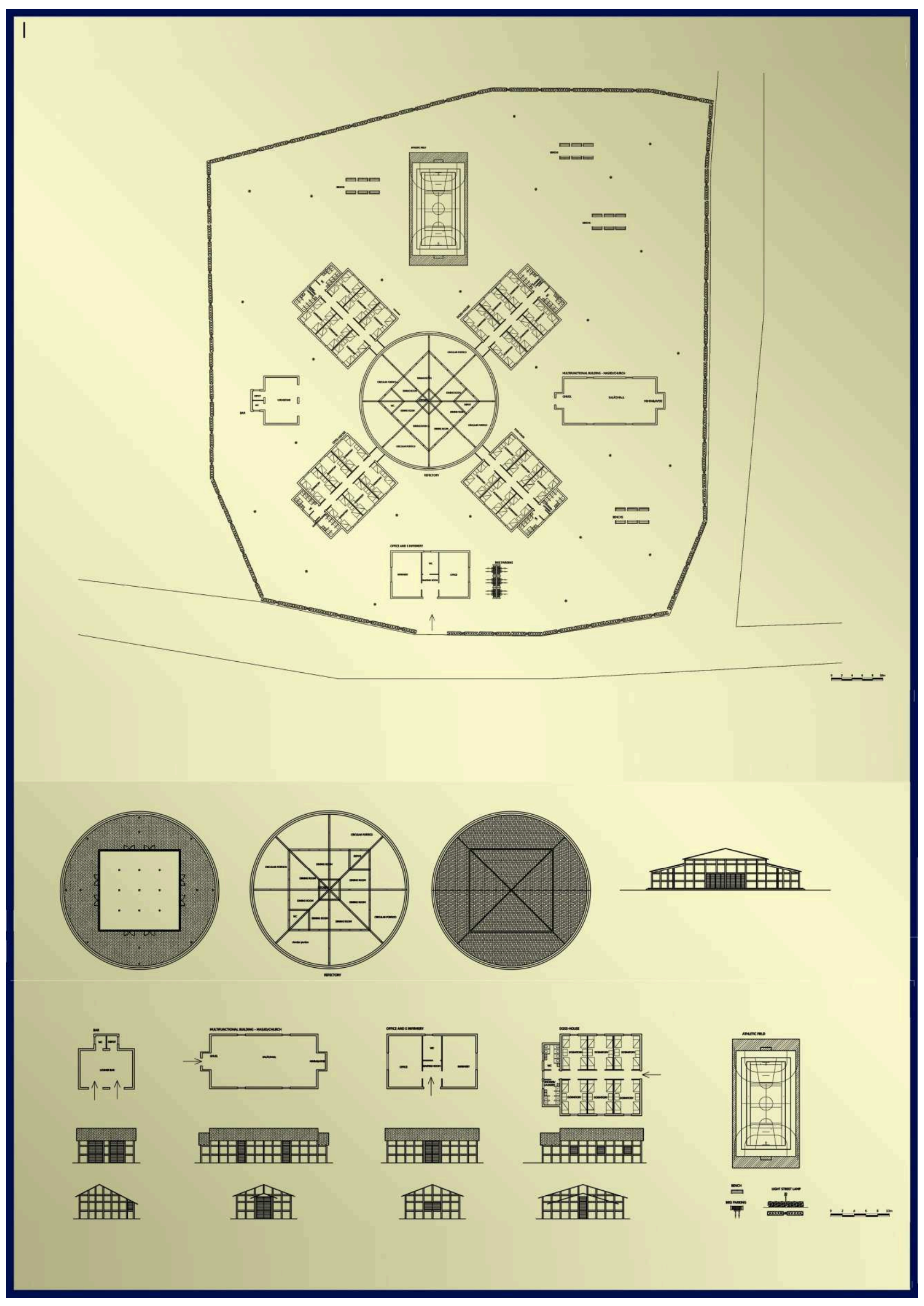

Fig. 3 - Environmental quality and resource efficiency 


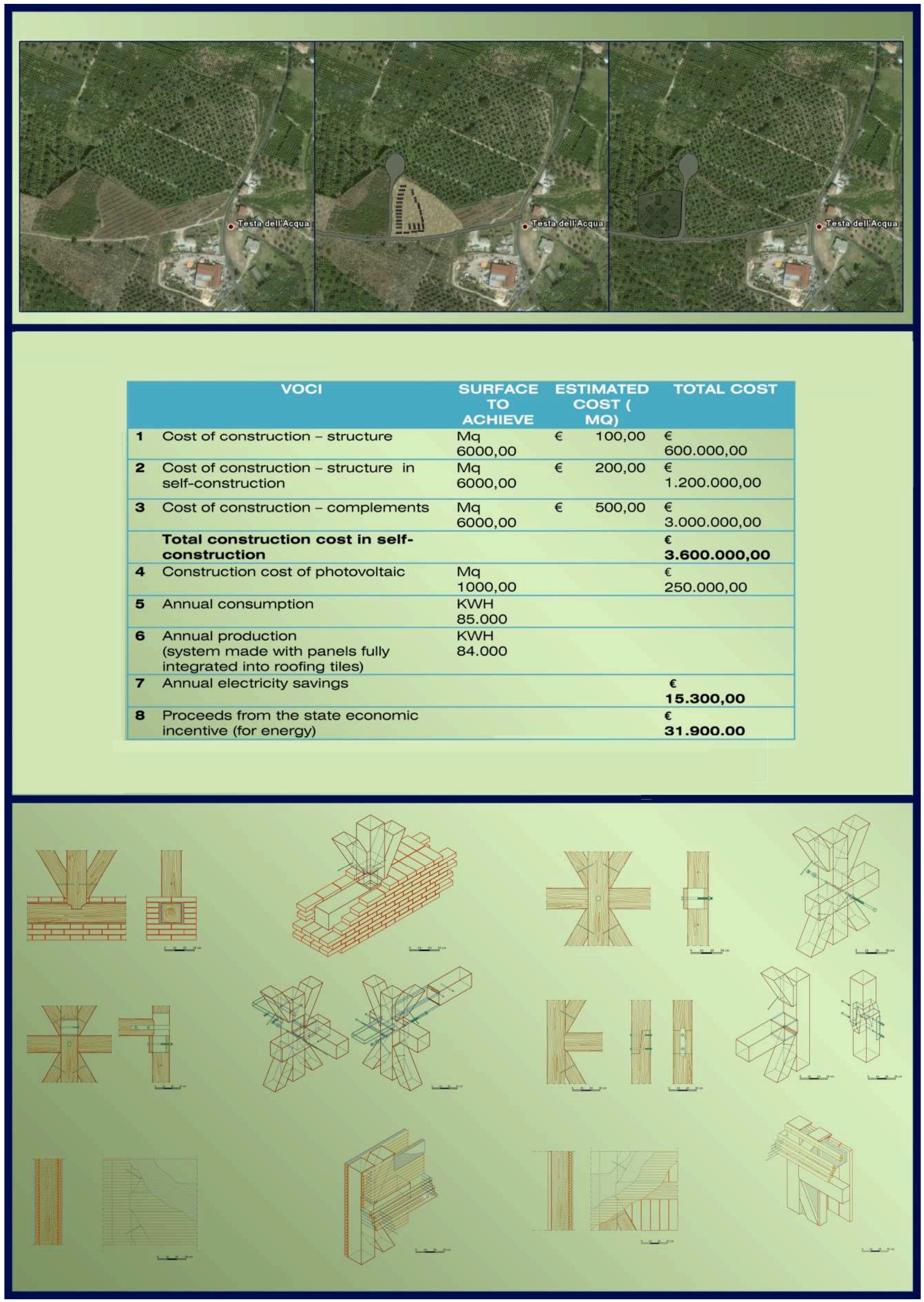

Fig. 4 - Economic compatibility 


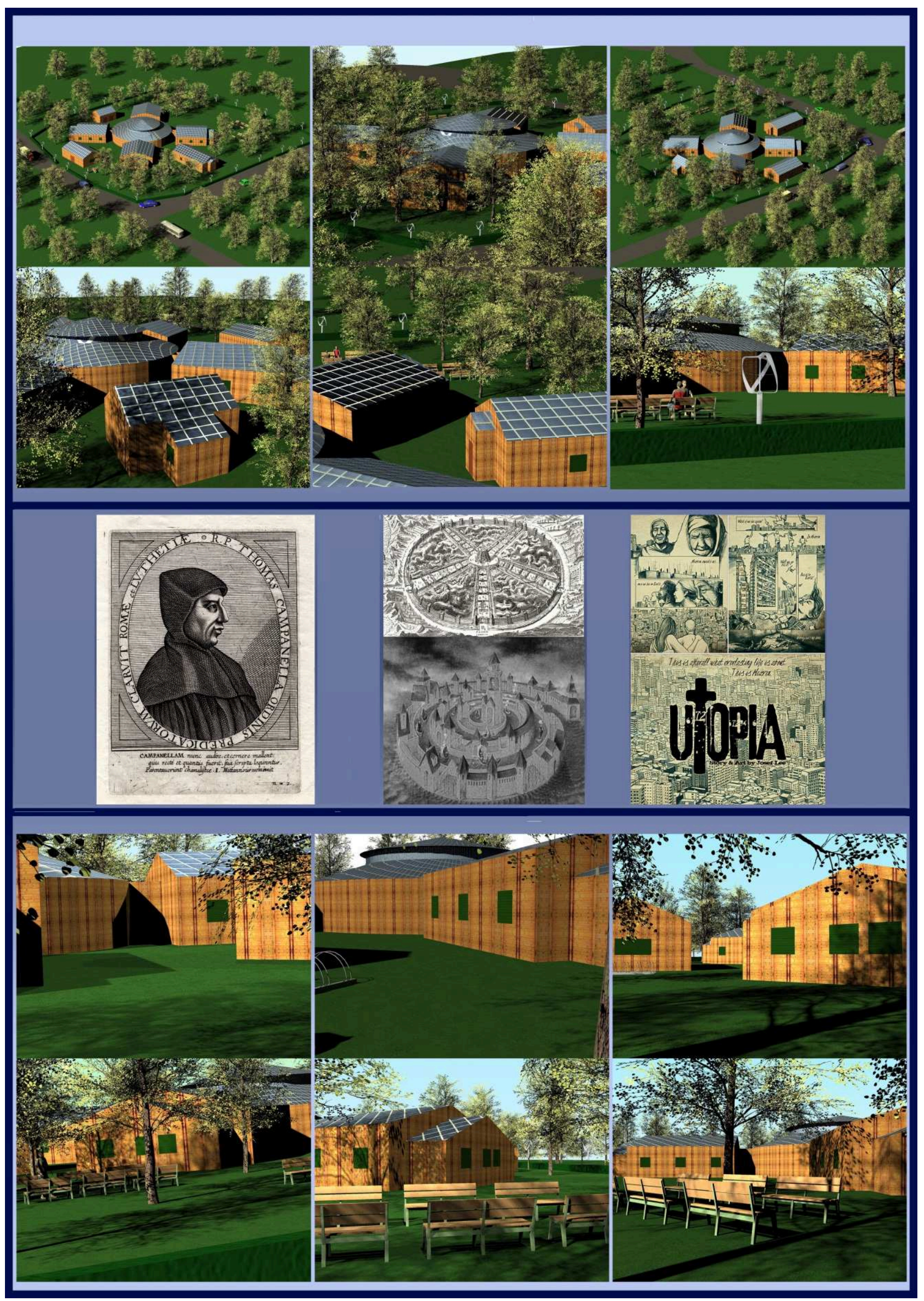

Fig. 5 - Contextual and aesthetic impact 
Moreover the framed house belongs to every age, from the Romans to Barbarians, from Middle Ages to the nineteenth Century; a lot of country has improved this technology and adapted it to its culture, demonstrating the transfer and innovation ability of this technology. Its transferability is demonstrated by the way it has been able to adapt in many different periods of civilization, preserving its structural peculiarities, because recognized in history as one of the best earthquake-proof houses. The Calabrian framed house fully expresses the concept of innovation, because the introduction of numerous technological variants makes it versatile for many uses and able to be easily restored, as demonstrated by some practical experiences, including the case of a timber framed church, assembled in Calabria, after the disastrous earthquake of 1908, and manually recovered by ourselves in 2001 during a didactic construction site, with a few simple tools and local materials, and the case of a 1:1 scale model of a framed wall, built in self-construction by no manual experienced students, in just 8 hours, with the few tools that are found in every house (an hammer, a saw, nails, and so on). The sustainability of this project resides also in its cost [6]; building this village will cost 3.6 million euros, compared to 2.8 million euros, spent to realize the current camp, and its management will cost 42 euro per person per day, compared with 80 euro per person per day of the current camp. In this way in 17 years and 2 months of functioning of village, it will be possible to recoup all the construction costs, through operating revenues. The current camp may come to the same aim only after 23 years and 8 months, given the high cost of ownership. A rational initial investment in sustainable construction permits in fact lower operating costs in long-life and therefore a more rapid amortization of initial construction investment [7].

\section{Conclusions}

The experience of this project, in addition to its social character, given by the peculiarity of the applicative case, tends to remind that knowledge of a place, of its environmental quality and of its anthropic genesis have to be one of fundamental elements to inspire a project, above all if it is aimed to transform a rural or urban context in which incidence of amenity and historicity is predominant and expression of a balance, that is not easy to preserve and maintain. Finally, under a technological point of view, this project is useful to demonstrate that to respect tradition, not rarely, coincides with needs of innovation, because a building tradition is often result of ancient changes and adaptations, which show an attitude to improvement, that is one of the main factors of innovation.

\section{References}

[1] D.E. Williams: Sustainable design: ecology, architecture and planning, Hoboken: John Wiley \& Sons, Hoboken (2007)

[2] F. De Filippi: Slum[e] scape: a challenge for sustainable development projects, Alinea, Firenze (2009)

[3] M.H. Contal: Sustainable design towards a new ethic in architecture and town planning Thomas Herzog, Birkhauser (2009)

[4] W. Clark Woodrow: Sustainable communities design handbook: green engineering, architecture, and technology, Butterworth-Heinemann, Burlington (2010). About the Calabrian timber frame house, see A. Bianco (edited by): La casa baraccata, GB Editoria, Rome (2010)

[5] M. Moro: The ecological house: sustainable architecture around the world, Whitestar, Vercelli (2011)

[6] S. Moore McGregor: Living homes: sustainable architecture and design, Chronicle books, San Francisco (2008)

[7] A. Almusaed: Biophilic and bioclimatic architecture: analytical therapy for the next generation of passive sustainable architecture, Springer, London (2011) 